\title{
Analysis of U.S. Sector of Services with Fama-French 5-Factor Model During the Covid-19
}

\author{
Yusen Feng ${ }^{1, \dagger}$, Tingjun $\mathrm{Li}^{2, *}{ }^{*}$, Ruoyu Zhao ${ }^{1, \dagger}$, Chennan Zhou ${ }^{3, \dagger}$ \\ ${ }^{1}$ Faculty of business, The Hong Kong Polytechnic University, Hong Kong 999077, China \\ ${ }^{2}$ Faculty of Economics, Communication University of China, Beijing 100020, China \\ ${ }^{3}$ Faculty of accounting, Shanghai Lixin University of Accounting and Finance, Shanghai 201620, China \\ *Corresponding author. Email: litingjun@cuc.edu.cn \\ These authors contributed equally.
}

\begin{abstract}
Covid-19 is the most widespread and devastating pandemic since the 20th century, which profoundly impacted the industries and the stock market, especially the service-related industries and stocks in the U.S. This paper aims to study the epidemic's impact on service-related industries in the U.S. and provide some quantitative indicators for investors to help them make investment decisions. Fama-French 5-Factor Model is adopted in this study to evaluate the factors that affect the stock price of the U.S. service sector, including Utilities, Communication, Personal Services, and Business Services. The data used for the analysis mainly comes from Kenneth R. French Data Library, which are the statistics of 5 factors and the daily return rate of the U.S. service sector from May 2019 to December 2020. Multiple Regression is adopted in this study to fit the model. The service-related industries' unique nature makes it the object of impacts caused by COVID-19. Using the Fama-French five-factor model, $t$-statistics is adopted to determine the significance of the five factors. The results indicate that the Mkt-Rf factor is always significant, representing the portfolio's risk premium. The HML factor of business service becomes significant after the epidemic when other service areas act oppositely to reduce the demands and business activities. In addition, due to the large market capitalization and scale effect of the Utility sector, the SMB factor maintains except Utility services turn out to be insignificant after the epidemic. Since most personal and business services depend on timely contact and many companies cannot follow this tendency, the RMW factor of Personal service and business service becomes significant after the epidemic when other two industries maintain. Also, the CMA factor acts in the same pattern as the RMW factor.
\end{abstract}

Keywords: Fama-French 5-Factor Model, COVID-19, US stock market, service-related industry

\section{INTRODUCTION}

\subsection{Background}

For the past thousands of years, humans have gradually completed the agricultural and industrial revolution and transitioned to a newly built informationbased society, where the service industry contributes the most to the national economy and dramatically changes people's way of living. Nowadays, the connection and contact between people are getting closer and more frequent as the scale of the service industry keeps increasing, which provides significant convenience for city dwellers. However, the service-led economy also renders a higher probability of the pandemic of infectious diseases, which must be highly considered in future development.

When COVID-19 swept the whole world at an unexpected speed in 2020, none of the countries had been ready for such a catastrophe. Facing this severe epidemic of COVID-19, all countries have adopted different levels of social distancing and virus isolation policies, which resulted in a conspicuously negative effect on the service industry, especially on those nononline service industries like restaurants, barbershops, laundries, etc.

As one of the most developed countries in today's world, the U.S. has the largest scale and the most diverse service industry and the most efficient stock market, meaning that the influence on the service 
industry can be accurately reflected in the corresponding stock price. At the same time, the country is still suffering from a pandemic of COVID-19 that renders a huge impact on the domestic service sector, which is reflected during the four circuit breakers that happened in the U.S. stock market in March 2020. Therefore, considering that the pandemic has caused an unprecedented impact on the U.S. service industry, it is necessary to evaluate how and to what extent did COVID-19 affect the service sector of the U.S. stock market to help investors adjust their investment portfolio of the service sector when encountering the black swan like COVID-19.

Capital Asset Pricing Model (CAPM) is an effective valuation model to evaluate the return rate of the stock, which makes a fundamental contribution to understanding the relationship between expected returns and market risks. Fama and French (1993) added size and book-to-market factors into the CAPM. After that, many new factor models are also developed. Many empirical results show Fama-French five-factor model is capable of explaining the stock returns better than the CAPM [1]. Hence, applying the Fama-French fivefactor model is helpful to figure out the factors that determine the return rate of a specific stock or sector. Meanwhile, we can see directly how and to what extent did COVID-19 affect the service sector by comparing the valid factors between before and after the pandemic.

\subsection{Related Research}

Karaömer researched the validity of the FamaFrench five factor model (FF5F) in Borsa Istanbul (BIST) during the 132-month period between July 2005 and June 2016. The sample comprises all firms which traded in the BIST during that period. The returns of the risk-free interest rate of 14 different intersection portfolios constructed based on size, market to book ratio, profitability, and investment factors have been used in the BIST. After researching the size, ME/BE, profitability, and investment factors, FF5F is effective to be applied on the BIST [2]. On the other hand, Foye started from a market perspective. He studied the fivefactor model between regions. Foye researched the performance of the Fama-French five-factor model in emerging markets. Foye collected samples from 18 countries from three different regions. First, he applied some empirical models in the asset pricing tests and then used the factor spanning test in testing redundant factors. Third, a summary asset pricing test was employed whether the five-factor model returns lower intercepts than the three-factor version. Foye concluded at last that the performance of the five-factor model is better than the three-factor in Eastern Europe and Latin America, but in Asia, the results show not much difference [3]. Back to the U.S. market, Yang et al. studied the effect of EGARCH-type volatilities and
SSAEPD errors on the Fama-French 5 factors model and the validity of FF5-SSAEPD-EGARCH model by applying the data of the industry of services in the US from Jul. 1990 to Feb. 2017. Method of Maximum Likelihood Estimation is used to estimate the parameters. Likelihood Ratio test and KolmogorovSmirnov test are used for model diagnostics. Akaike Information Criterion is used for model comparison. Empirical results show: 1) With EGARCH-typed volatilities and non-normal errors, the Fama-French 5 factors are still alive; 2) The new model fits the data better than Fama-French (2015)'s 5-factor model [4]. The outbreak of the new crown has had a huge impact on the U.S. investment market. Horv'ath and Wang's research results on the performance and explaining ability of Fama-French models on US stock markets during the selected crisis, including the latest Covid-19 outbreak, basing on 10 stocks from their data for the growth portfolio from January 1990 till March 2020, 6 value-weight portfolios based on size and book-tomarket, 6 value weight portfolios based on size and investment and 6 value-weight portfolios based on size and operating profitability monthly. Statistical parameter $\mathrm{R}^{\wedge} 2$ is examined to measure the explained rate of the $\mathrm{F}$ F model. GMM model is used for robustness test of Beta coefficient. Empirical results show that The Covid19 outbreak has led to a substantial drop in the $\mathrm{R}^{\wedge} 2$ during this event and all the beta model parameters are insignificant in the GMM model [5].

From the perspective of the U.S. public service industry, Switzer et al. have devoted themselves to estimating the COVID-19 pandemic challenge faced by the essential utilities and researched what reaction the utilities have. Switzer interviewed two utility managers of Missouri, especially focused on how they prevent their staffs from the virus and due with the problem that lack of labor force. In conclusion, Switzer put forward a strategy that? Reliance on mutual aid agreements so that the utilities could send staff and equipment to each other [6]. While gunway and kurtulmus analyze from the overall service industry, Gunay and Kurtulmus, investigated the impact of COVID-19 social distancing on the US service sector by applying four industry indexes (hotels, entertainment, restaurants, and airlines), where each index is consist of five companies with the largest market capitalization in a specific industry. The Kapetanios m-break unit root analysis, the DCCGARCH model, the Iterated Cumulative Sums of Squares (ICSS) test, and the Markov Regime-Switching Regression (MRSR) analysis are adopted to examine the statistical relationship among industries and test the influence of the COVID-19 pandemic on each. Empirical results show: 1) a negative influence from the pandemic took place on returns for entertainment and airline stocks; 2) the companies with less market capitalization in the hotel industry are more negatively affected; 3) there was no negative influence on stock 
returns of the restaurant industry [7]. From a global perspective, the performance of the power system under the epidemic has also led to research, Elavarasan et al. have researched the effect on the global electric system caused by the COVID-19 pandemic with some economic and technical dilemmas faced by the utilities. They collected the direct influences of power systems caused by pandemics, such as the demand for electric energy, found out the change of power consumption mode. At the same time, they borrowed certain ideas from the Indian utilities. Finally, they drew out a set of suggestions that could do benefit the global electric system during the COVID-19 pandemic period, which could assist the policy decision-maker in the future [8]. Scholars have also studied Twitter's decision-making judgments on users by scholars, Khyrina Airin Fariza Abu Samah et al. used the proposed conceptual model to present the world public emotion expressed on Twitter to visualize the communication service providers (CSP) reputation during the Covid-19 pandemic. Full Stack Web Development is used in the study, which means there are two parts: the back-end and the front-end. The model was constructed, and accuracy testing of the model was covered in the back-end section, which included data collecting, data pre-processing, and the Nave Bayes (NB) algorithm. The researcher detailed the system's flow and the intended interface in the front-end portion. The research concluded that the data obtained from the application can help with decision-making and provide an approximate estimate of how well a specific CSP is performing. The images in the application are all interactive, allowing the user to acquire better and more exact insights [9].

Covid-19 also caused waves in the U.S. financial market. Claudiu Tiberiu Albulescu investigated the impact of coronavirus pandemic uncertainty on financial market volatility (as measured by new infection cases and fatality ratios reported globally and in the United States). The researchers used the S\&P 500 3-month realized volatility index as a proxy for the volatility of the US financial markets and tested a basic Ordinary Least Squares (OLS) regression to look into the impact of the novel coronavirus on financial volatility. As a result, the effect of COVID-19 data reported worldwide is greater than the effect induced by data reported in the United States. The continuance of the COVID-19 situation and the ambiguity surrounding it have increased the volatility of US financial markets, affecting the global financial cycle [10]. Based on data analysis from China and the United States, Nuhu A. Sansa investigated the influence of the Covid-19 on financial markets in China and the United States from March 1, 2020, to March 25, 2020. It used a simple regression model to assess the influence of the Covid-19 on financial markets in China and the United States from March 1, 2020, to March 25, 2020. The analysis found a significant positive association between the
Covid-19 confirmed instances and all financial markets (Shanghai stock exchange and New York Dow Jones) in China and the United States from March 1, 2020, to March 25, 2020. That suggests the Covid-19 substantially impacted financial markets in China and the United States from March 1, 2020, to March 25, 2020 [11].

Hertog researched a four-dimensional model of (services) innovation to analyse the role played by Knowledge Intensive Business Services (KIBS) in innovation. Introducing research by Bilderbeek et al., the concepts of services innovation, its four dimensions, how they are connected to each other, and KIBS applications are well discussed. At the end of the article, it introduced the Nonaka \& Takeuchi model of knowledge creation to elaborate the differences between tacit knowledge and explicit knowledge and combined them with the four-dimensional model. Data is used to reveal the conditions of KIBS in Holland [12]. Compared with the former one, Muller discussed three specific questions. The first is the definitions of KIBS, the second is how KIBS has been investigated empirically, and the third is how have the dimensions of knowledge, innovation, and spatial proximity been integrated into the analysis. Different scholars have various thoughts about the definition of KIBS, and most of them define KIBS according to the NACE scheme and industrial classification. Investigation of KIBS has two phases: theoretical reflections, and a deeper empirical analysis of KIBS. According to an amount of empirical evidence, KIBS differs dramatically from other services in terms of innovation issues [13].

\subsection{Objective}

The objective of this study is to evaluate the changes and impacts of the United States service industry before and after the outbreak of the COVID-19 pandemic from 1st May 2019 to 31st December 2020, based on the Fama-French five-factor model. This study will provide some empirical experience regarding the impact of the epidemic on the service industry economy in the U.S., and it could propose relative reference value for some investment decisions of external investors as well as decision-makers and become useful to the Financial, major economic study through a series of industry studies.

\section{METHOD}

Capital Asset Pricing Model (CAPM) is a model to testify the primary relationship between the expected rate of return and risk. The equation of this model is:

$$
R_{i t}-R_{F}=\beta_{i} *\left(R_{m t}-R_{F}\right)
$$

Where $R_{i t}$ is the expected rate of return of stock of stock portfolio. $R_{F}$ is the rate of return for the risk-free asset. $R_{m t}$ is the average return rate of the stock market. 
$\beta_{i}$ is the systematic risk coefficient $\left(\beta_{i}=\frac{\operatorname{Cov}(R i t, R m t)}{\operatorname{Var}(R m t)}\right)$, which can reflect the volatility of a specific stock compared with the stock market. $R_{m t}-R_{F}$ represents the market risk premium, and it is always positive.

Fama and French's research found that CAPM cannot explain the difference between stock returns. At the same time, market capitalization, book-to-market ratio, and price-to-earnings ratio can provide an effective explanation. So, they added two factors SMB and HML, into the CAPM to establish an optimized model named Fama-French three-factor model. Therefore, the equation of the three-factor model is:

$$
\begin{aligned}
& R_{i t}-R_{F}=\beta_{1 i} *\left(R_{m t}-R_{F}\right)+\beta_{2 i} * S M B_{t}+\beta_{3 i} * \\
& H M L_{t}+\varepsilon_{i t}
\end{aligned}
$$

Where $S M B$ stands for small market capitalization minus big market capitalization, the equation of $S M B^{\prime} s$ calculation is (where S, B stand for the market capitalization of small and big stocks, H, M, L stand for the high, middle and low Book-to-Market Ratio of the stocks):

$$
S M B_{t}=\frac{S L_{t}+S M_{t}+S H_{t}}{3}-\frac{B L_{t}+B M_{t}+B H_{t}}{3}
$$

$H M L$ presents the high Book-to-Market Ratio minus low Book-to-Market Ratio, the equation of $H M L^{\prime} s$ calculation is (where H, L stand for the high and low Book-to-Market Ratio of the stocks):

$$
H M L_{t}=\frac{B H_{t}+S H_{t}}{2}-\frac{B L_{t}+S L_{t}}{2}
$$

$\beta_{1 i}, \beta_{2 i}$ and $\beta_{3 i}$ are the coefficients of factor $\left(R_{m t}-R_{F}\right), S M B_{t}$ and $H M L_{t}$, and $\varepsilon_{i t}$ is the regression residual. Therefore, the Fama-French three factor model could be applied into calculation.

Whereafter, Fama and French proposed the FamaFrench five-factor model to further explain the excess return of stock, the equation of Fama-French five-factor model is:

$$
\begin{aligned}
& R_{i t}-R_{F}=\beta_{1 i} *\left(R_{m t}-R_{F}\right)+\beta_{2 i} * S M B_{t}+\beta_{3 i} * \\
& H M L_{t}+\beta_{4 i} * R M W_{t}+\beta_{5 i} * C M A_{t}+\varepsilon_{i t}
\end{aligned}
$$

Where the newly added factor $R M W_{t}$ stands for robust operating profitability portfolios minus weak operating profitability portfolios, the equation of
$R M W^{\prime} S$ calculation is (where $\mathrm{R}, \mathrm{W}$ stand for the robust and weak operating profitability portfolios):

$$
R M W_{t}=\frac{B R_{t}+S R_{t}}{2}-\frac{B W_{t}+S W_{t}}{2}
$$

$C M A_{t}$ stands for conservative investment portfolios minus aggressive investment portfolios, the equation of $C M A^{\prime} s$ calculation is (where $\mathrm{C}$, A stand for the conservative and aggressive investment portfolios):

$$
C M A_{t}=\frac{B C_{t}+S C_{t}}{2}-\frac{B A_{t}+S A_{t}}{2}
$$

$\beta_{4 i}$ and $\beta_{5 i}$ are the coefficients of factor $R M W_{t}$ and $C M A_{t}$, and $\varepsilon_{i t}$ is the regression residual.

\section{RESULTS}

According to the Fama-French five-factor model, the service-related industries were adopted to investigate the impacts caused by COVID-19. As an industry whose nature is people-to-people interactions [14], the servicerelated industries are supposed to be against antiepidemic measures (reducing the interactive contacts of people). Hence, the services industry should be the area most directly impacted by COVID-19. In research, tstatistics is obtained by the method of multivariate regression, which applies the five factors as covariates. Setting $95 \%$ as the confidence interval, $H_{0}$ (null hypothesis) assumes that the coefficients are not zero and it is accepted when the confidence interval contains $\mathrm{t}$ value [15]

The service sector, including Utilities, Communication, Personal Services, and Business Services, classified by Kenneth R. French's research team, is selected as the research object. 10152 pieces of data on the Fama-French 5 Factors $\left(R_{m t}-\right.$ $\left.R_{F}, S M B_{t}, H M L_{t}, R M W_{t}, C M A_{t}\right)$ [Daily] are adopted from Kenneth R. French Data Library [16] as the datasets and applied to the Fama-French five-factor model. To better describe the impacts on the five factors, these two datasets are divided into two time periods: $5 / 2019-2 / 2020$ is the before COVID-19 period, and $3 / 2020-12 / 2020$ is the after COVID-19 period.

Table 1. The estimated coefficients of the five factors and their corresponding t-statistics for the period before and after COVID-19

\begin{tabular}{cccccccccc}
\hline Period & Industry & \multicolumn{2}{c}{ Util } & \multicolumn{2}{c}{ Telcm } & \multicolumn{2}{c}{ Persv } & \multicolumn{2}{c}{ Bussv } \\
\cline { 2 - 9 } Before & Factor & Coefficient & t Stat & Coefficient & t Stat & Coefficient & t Stat & Coefficient & t Stat \\
\hline & Mkt-RF & 0.560 & 10.900 & 0.750 & 17.760 & 0.720 & 15.180 & 1.020 & 31.734 \\
& SMB & -0.380 & -3.920 & -0.100 & -1.270 & 0.370 & 4.170 & 0.011 & 0.178 \\
& HML & -0.098 & -0.990 & 0.150 & 1.850 & -0.040 & -0.450 & -0.364 & -5.864 \\
& RMW & -0.640 & -4.010 & -0.200 & -1.490 & 0.290 & 1.940 & -0.024 & -0.236 \\
& CMA & 1.000 & 5.260 & 0.120 & 0.770 & 0.000 & 0.010 & -0.221 & -1.849 \\
& Mkt-RF & 0.970 & 24.300 & 0.789 & 35.462 & 0.889 & 28.582 & 1.124 & 51.582 \\
& SMB & -0.150 & -1.500 & -0.080 & -1.368 & 0.589 & 7.350 & 0.031 & 0.560
\end{tabular}




\begin{tabular}{cccccccccc} 
After & HML & 0.180 & 2.170 & 0.223 & 4.728 & 0.265 & 4.022 & 0.074 & 1.593 \\
& RMW & -0.460 & -2.670 & 0.120 & 1.218 & 0.561 & 4.197 & -0.185 & -1.977 \\
& CMA & 0.990 & 4.500 & 0.000 & -0.036 & -0.506 & -2.955 & -0.531 & -4.428 \\
\hline
\end{tabular}

From table 1, it can be observed that only the market coefficient of business services is greater than 1 . The HML factor of business service becomes significant after the epidemic when other service areas act oppositely. The SMB factor maintains except for utility service (be insignificant after COVID-19). The RMW factor of personal service and business service turn out to be significant after the epidemic while utility service's remains significant and telecommunication's remains insignificant. The CMA factor shows the same pattern as the RMW factor.

\section{DISCUSSION}

\subsection{Mkt-RF}

The Mkt-RF factor represents the risk premium of holding a portfolio consisting of all stocks in the capital market, and it is significant for the service-related sectors before and after COVID-19, according to Table 1. Meanwhile, the beta coefficients of Utilities, Telecommunication, and Personal Services are positive and raise to a different extent after the epidemic. In addition, the beta coefficients are very close to 1 , meaning that the service-related stocks move almost in line with the market portfolio during the observation period.

Suffering from the impact of COVID-19, people were losing their confidence in the economy when thousands of infected cases were reported, and the S\&P index also experienced a slump in March 2020 from 3393.52 to 2191.86 , which results in a general decline of every sector, including service-related sectors. Later, as some social distancing and medical care measures worked and people began to get vaccinated, the S\&P index bottomed out as service-related sectors and recovered to 3756.07 at the end of 2020 .

Described as Systemic Risk, the Black Swan Event like COVID-19 tend to shock the whole capital market, which is unavoidable. Obviously, service-related stocks are more likely to fluctuate simultaneously with the market than usual because all industries are impacted almost equally during the outbreak, and the beta coefficient of Mkt-RF reflects this.

\section{2. $S M B$}

According to Table 1, the Utility sector has a significant, negative beta coefficient of SMB before COVID-19, which becomes insignificant after COVID19. In contrast, the beta coefficient of the Personal Services sector is significant and positive during both before and after COVID-19. In addition, coefficients of
SMB are insignificant to the rest two sectors during the observation period.

SMB can be considered as a portfolio that buys stocks with small-cap and shorts the large-cap ones. The utility sector includes stocks of Electric, gas \& sanitary services, Water supply, etc., which always have a large market capitalization because of the scale effect. So, the return of the Utility sector must be higher if large-cap stocks perform well, while SMB portfolios might suffer loss by shorting those large-cap stocks. This is the reason why the beta coefficient of SMB is significantly negative for the Utility sector. Similarly, the Personal Services industries can be relatively small for their specialized and personalized services like laundry, cleaning \& garment services, so the return of the Personal Services sector is positively correlated to the SMB portfolio with a positive beta coefficient.

Compared with the Utility sector, the Personal Services sector suffered a much more negative impact during COVID-19 because social distancing made faceto-face personal services impossible. What's worse, the small-cap companies in the Personal Services sector are inherently weaker than those large-cap companies in the Utility sector when facing any Black Swan Event. Hence, after the outbreak of COVID-19, both small and large-cap stocks experienced a rapid decline, but those small-cap stocks have fallen even more. In the meantime, returns of the Utility sector were no longer correlated to the SMB portfolio, which was only affected by large-cap stocks with less decline. On the contrary, influenced by a sharp decrease from small-cap stocks, returns of the Personal Services sector were more significantly related to the SMB portfolio. This is why the Personal Services sector's beta coefficient of SMB increases while the Utilities sector's becomes insignificant after COVID-19.

\section{3. $H M L$}

As shown in Table 1, it can be observed that Utilities, Telecommunications, and Personal Services represent insignificant HML before COVID-19 which turn out to be significant after COVID-19. And business services act in a diverse way. Its HML becomes insignificant and negative after the epidemic.

Before the epidemic, these service-related industries included different companies with different service coverages and various concentrated subsectors. Hence, it is difficult to use a uniform standard, book-to-market, to evaluate the performances of those companies' stock prices. There are some reasons to explain why the mentioned industries' HML turns significant after 
COVID-19. People have to spend more time staying home, and the reactions between people rely on telecommunication to a certain degree. Apart from that, to reduce the aggregation, the companies who provide personal services catch the chance to cater to the demands of anti-epidemic measures, and its stock price is indicated to perform well. Therefore, those three service-related subsectors bloomed compared to other categories after the epidemic, and the HML can better forecast their stock return.

For business services companies, business activities decreased dramatically due to the uncertainty with the epidemic, and it caused the reduction in the demands and profits of business services companies. Therefore, its stock price changes negatively, and HML becomes insignificant due to the epidemic.

\section{4. $R M W$}

The RMW factor is not remarkable in explaining the change of stock price in personal service and business in 2019. However, after the outbreak of the COVID-19 pandemic, RMW becomes an important factor, which means their $t$ value is bigger than 1.96. The $t$ value of personal service is positive; the $t$ value of business service is negative.

During the pandemic, most personal service and personal service are influenced. As their management is relying on offline contact to a great extent, which is different from telecommunication, and that is why their revenue decreased significantly. Unlike utilities, revenue is extremely significant for business service and personal service because they are profitable industries, so the change of stock price has a strong relationship with RWM after the pandemic because the investors wish the company could have an increasing income.

For example, according to a restaurant brands international, the revenue of the last three quarters is extremely low, especially in the second quarter which is missed by 2.23 million dollars. Correspondingly, its stock price is unsatisfactory, much lower than the stock price before March 2020 [17]. Its profitability has fallen, which led to the plummeting of the stock market. The investors pay close attention to the company's profitability in personal service and business service, expecting the rebound of their revenue, which they depend on to make the investment decision. In conclusion, the RWM factor's effect on the investment decision in personal service and business service became significant after the COVID-19 pandemic.

\section{5. $C M A$}

CMA is the rate of return of the investment factor. It is a factor that calculates the excess return brought by the investment level. It measures the difference between the high and low reinvestment ratios of the company's stock portfolio returns. From the results, comparing before and after the outbreak, the performance of factor CMA in personal services and business services has changed from a redundant variable to a significant variable, which obviously indicates that they have changed greatly during the time period. The public service industry remains significant, while the telecommunications service is still insignificant.

Affected by the epidemic, the service industry in the United States has suffered a more obvious impact. Most companies adopt online office methods, while public utilities are necessary for people's daily life. Therefore, from the results, the communication and utility industry has been less affected. However, the CMA in the personal service and business service industries has a negative slope. The result shows that the two industries are subject to more obvious fluctuations. The difference in returns from investing in small service providers and investing in hot companies is similar.

From the perspective of the personal service industry, according to research by Gunay and Kurtulmus, a negative influence from the pandemic took place on returns for entertainment and airline stocks [18]; therefore, investors may choose more aggressive investment options. From the business services industry perspective, the new crown epidemic has had a greater impact on the US financial services industry. In the selected research data period, the small and mediumsized portfolios of the US stock market and large investment portfolios have relatively small differences, which also shows that its stocks. The volatility of the market is relatively large, so the investment level is relatively similar.

\section{CONCLUSION}

This article investigates the situation about different branches of service-related industries. It applies FamaFrench 5-Factor Model to discuss the influence on different factors in the service industry before and after the COVID-19 pandemic. It is explored that after the pandemic, the HML factor of business service, the SMB factor of utilities, the RMW and CMA factors of personal and business service turn out to be significant. The regression results can effectively help investors make investment decisions and adjust their investment portfolios during the epidemic. We hope that our research can help make portfolio selections before the epidemic disappears ultimately.

\section{REFERENCES}

[1] Yang, Q., Li, L., Zhu, Q., \& Mizrach, B. (2017). Analysis of US sector of services with a new Fama-French 5-factor model. Applied Mathematics, 8(9), 1307-1319. 
[2] Acaravci, S. K., \& Karaomer, Y. (2017). FamaFrench five factor model: evidence from Turkey. International Journal of Economics and Financial Issues, 7(6), 130-137.

[3] Foye, J. (2018). A comprehensive test of the Fama-French five-factor model in emerging markets. Emerging Markets Review, 37, 199222.

[4] Yang, Q., Li, L., Zhu, Q., \& Mizrach, B. (2017). Analysis of US sector of services with a new Fama-French 5-factor model. Applied Mathematics, 8(9), 1307-1319.

[5] Horváth, D., \& Wang, Y. L. (2021). The examination of Fama-French Model during the Covid-19. Finance Research Letters, 41, 101848.

[6] Switzer, D., Wang, W., \& Hirschvogel, L. (2020). Municipal Utilities and COVID-19: Challenges, Responses, and Collaboration. The American Review of Public Administration, 50(6), 577-583.

[7] Gunay, S., \& Kurtulmuş, B. E. (2021). COVID19 social distancing and the US service sector: What do we learn?. Research in international business and finance, 56, 101361.

[8] Elavarasan, R. M., Shafiullah, G., Raju, K., Mudgal, V., Arif, M. T., Jamal, T., ... Subramaniam, U. (2020). COVID-19: Impact Analysis and Recommendations for Power Sector Operation. Applied Energy, 279, 115739115739

[9] Samah, K. A., Badarudin, I., Ibrahim, S., Moketar, N. A., \& Riza, L. (2021). Naïve Bayes Twitter sentiment analysis in visualizing the reputation of communication service providers: During Covid-19 pandemic. Turkish Journal of Computer and Mathematics Education, 12(5), 1753-1764.

[10] Albulescu, C. T. (2021). COVID-19 and the United States financial markets'volatility. Finance Research Letters, 38, 101699.

[11] Sansa, N. A. (2020). The Impact of the COVID19 on the Financial Markets: Evidence from China and USA. Social Science Research Network.

[12] Hertog, P. D. (2000). Knowledge-intensive business services as co-producers of innovation. International journal of innovation management, 4(04), 491-528.
[13] Muller, E., \& Doloreux, D. (2009). What we should know about knowledge-intensive business services. Technology in society, 31(1), 64-72.

[14] Teoh, J. Y. C., Ong, W. L. K., Gonzalez-Padilla, D., Castellani, D., Dubin, J. M., Esperto, F., ... \& UroSoMe Working Group. (2020). A global survey on the impact of COVID-19 on urological services. European urology, 78(2), 265-275.

[15] Connor, G., \& Sehgal, S. (2001). Tests of the Fama and French model in India.

[16] French, K. R. (n.d.). Kenneth R. French Data Library. Kenneth R. French - Data Library. $\mathrm{http} / / / \mathrm{mba}$.tuck.dartmouth.edu/pages/faculty/ken. french/data library.html.

[17] QSR - Restaurant Brands International Inc,2021.https://seekingalpha.com/symbol/QSR/ earnings

[18] Gunay, S., \& Kurtulmuş, B. E. (2021). COVID19 social distancing and the US service sector: What do we learn?. Research in international business and finance, 56, 101361. 